\title{
Alimentación de ovinos en regiones del trópico en Colombia
}

\author{
Sheep feeding in tropical regions of Colombia
}

\section{Alimentação de ovinas em regiões tropicais da Colômbia}

\author{
Víctor Alexis Avendaño Rodríguez ${ }^{1}$ y Cesar Augusto Navarro Ortiz ${ }^{2}$ \\ ${ }^{1}$ Médico Veterinario Zootecnista, Universidad de los Llanos y ${ }^{2} \mathrm{MVZ}$, MSc, \\ Estudiante Doctorado en Ciencias Agrarias, Docente Universidad de los Llanos.

\section{cesar.navarro@unillanos.edu.co}

Recibido 31 de agosto 2020, aprobado 2 de diciembre 2020

\section{RESUMEN}

En este trabajo se hace una exploración minuciosa para mostrar al sistema de producción ovina como una alternativa productiva y promisoria para un futuro próximo de las regiones tropicales Colombianas, correlacionado con la relevancia presentada a nivel nacional en los últimos tiempos y opción socio económica viable para los pequeños productores de los centros poblados afectados por el posconflicto; resaltando la falta de tecnificación para este eslabón pecuario por la baja productividad por el manejo alimenticio, el desconocimiento de la especie y la cultura bovina de tradición. Con la revisión del material bibliográfico y la contextualización de la región intertropical, se determinan las necesidades de enfatizar, en orden de importancia, la producción eficiente de forrajes de alto valor nutricional y biológico, un esquema de selección genética detallado analizando la raza y sus bondades, y la visión empresarial competitiva para producción de carne. Además de los factores más relevantes para evaluar la eficiencia de la dieta, por medio de la condición corporal y el estatus sanitario de los individuos. Lo anterior favoreció para concluir, la necesidad de establecer en la zona un paquete tecnológico integral, sirviendo de base para la organización de las producciones actuales y el establecimiento adecuado de futuras granjas ovinas, desde el aspecto nutricional hasta el factor comercial. 
Palabras clave: Ovinocultura, trópico bajo, pastos, forrajes, requerimientos nutricionales, producción de carne, suplementación.

\begin{abstract}
In this work a thorough exploration is made to show the sheep production system as a productive and promising alternative for the near future of the of the Colombian tropical regions, correlated with the relevance presented at the national level in recent times and a viable socio-economic option for small children. producers of the population centers affected by the post-conflict; highlighting the lack of technology for this livestock link due to low productivity due to food management, ignorance of the species and the traditional bovine culture. With the revision of the bibliographic material and the contextualization of the intertropical region, the needs to emphasize, in order of importance, the efficient production of forages of high nutritional and biological value, a detailed genetic selection scheme analyzing the breed and its benefits are determined, and the competitive business vision for meat production. In addition to the most relevant factors to evaluate the efficiency of the diet, by means of the corporal condition and the sanitary status of the individuals. The foregoing favored, to conclude, the need to establish an integral technological package in the area, serving as a basis for the organization of current productions and the proper establishment of future sheep farms, from the nutritional aspect to the commercial factor.
\end{abstract}

Keywords: Sheep farming, low tropics, pastures, forages, nutritional requirements, meat production, supplementation.

\title{
RESUMO
}

Neste trabalho é feita uma exploração detalhada para mostrar o sistema de produção de ovinos como uma alternativa produtiva e promissora para o futuro próximo da das regiões tropicais colombianas, correlacionada com a relevância apresentada a nível nacional nos últimos tempos e uma opção socioeconómica viável para pequenos. produtores de centros povoados afetados pelo pós-conflito; destacando a falta de modernização para este elo pecuário devido à baixa 
produtividade devido ao manejo alimentar, desconhecimento da espécie e cultura bovina tradicional. Com a revisão do material bibliográfico e a contextualização da região intertropical, é necessário enfatizar, em ordem de importância, a produção eficiente de forragens de alto valor nutricional e biológico, um detalhado esquema de seleção genética analisando a raça e seus benefícios. e a visão competitiva de negócios para a produção de carnes. Além dos fatores mais relevantes para avaliar a eficácia da dieta alimentar, por meio da condição corporal e do estado de saúde dos indivíduos. O exposto favoreceu, para concluir, a necessidade de se estabelecer um pacote tecnológico abrangente na área, servindo de base para a organização das produções atuais e o adequado estabelecimento de futuras granjas ovinas, desde o aspecto nutricional ao comercial.

Palavras-chave: Criação de ovinos, baixos trópicos, pastagens, forragens, exigências nutricionais, produção de carne, suplementação.

\section{CONCEPTOS DE GANADERÍA OVINA Y OVINOCULTURA}

La ovinocultura se define como la cría de ovejas, económicamente rentable y en equilibrio con el medio (Cordero et al., 2016). Dentro de las especies animales con fines zootécnicos en el mundo, la oveja ocupa uno de los primeros lugares de propagación, con un total aproximado de 1202.5 millones de cabezas, distribuidas el $40.5 \%$ en Asia, $26.1 \%$ en África, $13 \%$ en Europa, $12.1 \%$ en Oceanía y $8.2 \%$ en América, siendo China, Australia, India, Irán y Sudán los principales países productores (FAO, 2018). Los ovinos también son la especie de mayor heterogeneidad fenotípica y genotípica (Cordero et al., 2016).

En las últimas décadas la producción ovina tradicional, extensiva y de gran escala en América Latina, ha ido concentrándose paulatinamente en regiones marginales, en las que no compite con actividades agropecuarias de desarrollo moderno y de escala empresarial; donde la mayoría de los pequeños productores de los países en desarrollo crían ovejas por su carne o para la venta como ganado en los mercados locales; igualmente a pesar de que el consumo de carne y leche de ovejas parecería limitado mundialmente, en zonas marginales desempeña un papel muy 
importante en las dietas de la población más vulnerable como parte sustancial de la oferta proteica (Ganzábal et al., 2016; FAO, 2018; Morand-Fehr y Boyazoglu, 1999). Siendo los ovinos una especie productiva de la cual el hombre, desde la prehistoria, ha obtenido alimento y vestido a partir de los productos que se obtienen de ellos, tales como: carne, lana, leche y pieles; ligados a las tradiciones culturales y sociales en diferentes regiones del mundo, desarrollando principalmente productos de tipo artesanal, y manteniendo, en gran medida una explotación y comercialización de tipo informal (Romero, 2010; Rúa y Pabón, 2015).

\section{Características de los ovinos}

El ganado ovino, según Espinal et al., (2006) es uno de los mejores medios para revalorizar importantes áreas del territorio nacional y mundial, debido a que este tipo de ganado se destaca por una serie de características que le hacen insustituible, y entre ellas cabe remarcar varios aportes económicos y sociales que esta especie ofrece, como son:

- Aprovechar para su alimentación básica, una serie de recursos herbáceos y de subproductos agrícolas que pueden sustituir el uso de balanceados comerciales en su alimentación.

- Debido a su reducida dimensión corporal se adaptan mucho mejor que el ganado vacuno a áreas poco productoras (semiáridas, baja pluviosidad, con topografía accidentada, etc.). La oveja, en general, se puede considerar como una especie cosmopolita y de fácil manejo que se adapta relativamente bien a condiciones climáticas diversas.

- Por sus características de pastoreo (en general gregario), mecanismo de aprehensión (control de arvenses) y por su capacidad para consumir algunos subproductos agrícolas, la oveja se complementa muy bien con ciertas explotaciones agrícolas (palma africana, cítricos, frutales caducifolios y cereales).

- Como ganadería de ocupación de áreas desfavorecidas induce el asentamiento de familias en zonas donde frecuentemente la única alternativa es la producción de la ganadería ovina. 
De acuerdo a la estructura de los sistemas de producción, el rebaño y los ovinos se organizan, por edad, sexo y estado fisiológico, en las siguientes categorías (González y Tapia, 2017):

- Corderos: Hembras y Machos, menores a 12 meses, aún con diente de leche.

- Borregos: Hembras y Machos, entre 12 y 20 meses, con muda de las pinzas (primeros incisivos)

- Oveja: Hembra, mayor a 20 meses, con muda de pinzas y primeros medios.

- Capón: Macho castrado, mayor a 20 meses, con muda de pinzas y primeros medios.

- Carnero: Macho entero, mayor a 20 meses, con muda de pinzas, primeros medios, y en algunos casos, segundos medios.

\section{Parámetros zootécnicos en ovinos}

Se definen como una correlación entre la caracterización y tipificación; como caracterización, por la descripción de características e interrelaciones de una organización o grupo de animales (nacimientos, mortalidad, alimentación); como tipificación, porque está relacionada con la construcción de grupos (selección y categorización), cuya base son las características observadas en la realidad y en determinadas condiciones medioambientales (Cruz et al., 2013). Los parámetros productivos y reproductivos en ovinos se describen en la Tabla 1 (Lôbo et al., 2009; Otte y Chilonda, 2002; Cansino et al., 2009; Vásquez et al., 2011).

Los parámetros seleccionados determinan la dinámica de la población y la productividad bruta del sistema ovino la cual generalmente está estrechamente vinculada con los parámetros básicos (zootécnicos) de producción, como la fertilidad y la mortalidad, donde la diferencia y los valores entre éstos, permiten la toma de decisiones y una gestión eficiente para el comercio e inversión para el crecimiento del hato (Otte y Chilonda, 2002). Sin embargo, los parámetros varían de acuerdo a las condiciones medio ambientales, el manejo y el método de muestreo o determinación, como para establecerlos de base hacia todas las poblaciones ovinas (Lôbo et al., 2009). 
Tabla 1. Parámetros zootécnicos de los ovinos

\begin{tabular}{|c|c|c|c|}
\hline Característica & $\begin{array}{c}\text { Promedio } \pm \\
\text { DS }\end{array}$ & Característica & $\begin{array}{c}\text { Promedio } \\
\text { DS }\end{array}$ \\
\hline Peso al nacimiento $(\mathrm{kg})$ & $3.84 \pm 0.86$ & Duración de celo (días) & $15.3 \pm 2.08$ \\
\hline Peso al destete $(\mathrm{kg})$ & $15.52 \pm 3.99$ & Intervalo monta-parto (días) & $\begin{array}{l}164.72 \pm \\
9.04\end{array}$ \\
\hline Peso al sacrificio (kg) & $31.96 \pm 6.22$ & Fertilidad (\%) & $78.3 \pm 5.3$ \\
\hline $\begin{array}{l}\text { Peso de hembras maduras } \\
\qquad(\mathrm{kg})\end{array}$ & $29.2 \pm 6.4$ & Prolificidad (Un) & $1.3 \pm 4.2$ \\
\hline Peso de machos maduros (kg) & $31.3 \pm 0.44$ & Concepción (\%) & $91 \pm 2.8$ \\
\hline Peso al año de edad $(\mathrm{kg})$ & $41.15 \pm 7.64$ & Natalidad (\%) & $121.3 \pm 9.3$ \\
\hline $\begin{array}{l}\text { Ganancia de peso (GP) } \\
\text { (kg/día) }\end{array}$ & $\begin{array}{l}0.213 \pm \\
0.063\end{array}$ & Descarte anual (\%) & $20.3 \pm 8$ \\
\hline GP destete-sacrificio (kg/día) & $\begin{array}{l}0.234 \pm \\
0.085\end{array}$ & Pubertades machos (días) & $\begin{array}{c}189.76 \pm \\
36.1\end{array}$ \\
\hline $\begin{array}{l}\text { GP destete-año de edad } \\
\text { (kg/día) }\end{array}$ & $\begin{array}{l}0.087 \pm \\
0.024\end{array}$ & Pubertad hembras (días) & $252 \pm 8$ \\
\hline Consumo de alimento $(\mathrm{kg})$ & $1.30 \pm 0.15$ & $\begin{array}{l}\text { Cantidad de hembras/macho } \\
\text { (Un) }\end{array}$ & 25 a 35 \\
\hline Conversión alimenticia (kg) & $4.07 \pm 1.05$ & Mortalidad en lactancia (\%) & $28.2 \pm 11$ \\
\hline Eficiencia alimenticia (Un) & $0.3 \pm 0.15$ & Mortalidad en destete (\%) & $9 \pm 2.5$ \\
\hline Edad al destete (días) & $95.9 \pm 1.7$ & Mortalidad en levante (\%) & $8.3 \pm 3.3$ \\
\hline Edad al sacrificio (días) & $184 \pm 42$ & Mortalidad en ceba (\%) & $5.3 \pm 2.3$ \\
\hline Edad al primer parto (días) & $\begin{array}{l}532.71 \pm \\
90.20\end{array}$ & Rendimiento en canal (\%) & $48.43 \pm 1.8$ \\
\hline Intervalo entre partos (días) & $\begin{array}{c}267.23 \pm \\
56.87\end{array}$ & Proporción carne (\%) & $63.3 \pm 1.7$ \\
\hline Intervalo parto-celo & $16.26 \pm 1.45$ & Proporción hueso (\%) & $21.30 \pm 1.45$ \\
\hline Días abiertos (días) & $21.4 \pm 2.9$ & Proporción grasa (\%) & $13.83 \pm 2.80$ \\
\hline Duración de gestación (días) & $\begin{array}{l}150.93 \pm \\
3.20\end{array}$ & & \\
\hline
\end{tabular}

Fuente: Adaptado de: Lôbo et al.,(2009); Otte y Chilonda, (2002); Cansino et al., (2009); Vásquez et al., (2011).

\section{Heredabilidad}

Este concepto es uno de los más importantes en la genética cuantitativa, porque indica cuanto de las diferencias entre individuos, en promedio, se transmite a la progenie o descendencia, para una característica en particular, siendo un factor 
fundamental para predecir el fenotipo de la cría, pero sin considerarse como valor absoluto (Ochoa, 1991). El intervalo de este parámetro es de 0 a 1, indicando cerca de cero un fuerte componente ambiental, mientras que valores cercanos a la unidad (1) representan una elevada influencia genética y un bajo componente ambiental. La heredabilidad es una medida específica de la población y sólo es válida para el ambiente donde se ha determinado (Bécquer, 2005). Los valores de heredabilidad de la ovinocultura se presentan en la Tabla 2 (Castellaro et al., 2015; Mathis y Ross, 2005; Creangâ et al., 2007; Ferrer, 2017; Fogarty, 2006; Leymaster, 2002).

Tabla 2. Valores de heredabilidad (\%) en ovinos

\begin{tabular}{|c|c|c|c|}
\hline Característica & Heredabilidad & Característica & Heredabilidad \\
\hline Peso al nacimiento & $0.15-0.24$ & $\begin{array}{l}\text { Rendimiento de la } \\
\text { canal }\end{array}$ & $0.25-0.40$ \\
\hline Peso al destete & $0.20-0.29$ & Área de lomo & $0.35-0.50$ \\
\hline Peso al sacrificio & $0.26-0.28$ & $\begin{array}{c}\text { Grasa sobre lomo } \\
(\mathrm{mm})\end{array}$ & $0.30-0.60$ \\
\hline Ganancia diaria de peso & $0.30-0.40$ & Peso de la canal & $0.35-0.50$ \\
\hline $\begin{array}{l}\text { Îndice de conversión } \\
\text { alimenticia }\end{array}$ & $0.20-0.40$ & Peso por cortes & $0.20-0.45$ \\
\hline Peso adulto & $0.2-0.4$ & Terneza & $0.05-0.30$ \\
\hline Longitud de vellón & $0.30-0.65$ & Fertilidad & $0.05-0.15$ \\
\hline Calidad de vellón & $0.20-0.60$ & Prolificidad & $0.05-0.20$ \\
\hline Rendimiento de lana & 0.52 & Tasa ovulatoria & $0.13-0.12$ \\
\hline Lanolina & 0.30 & Habilidad materna & $0.30-0.40$ \\
\hline Rendimiento total de leche & $0.1-0.41$ & Ubicación de pezones & $0.14-0.25$ \\
\hline Nacimientos múltiples & 0.1 & Forma de la ubre & $0.14-0.25$ \\
\hline Productividad por oveja & $0.14-0.24$ & Resistencia a parásitos & $0.30-0.50$ \\
\hline
\end{tabular}

Fuente: Castellaro, (2016); Creangâ et al., (2007); Ferrer (2017); Fogarty, (2006).

Valores de heredabilidad menores a 0.2 son considerados bajos; entre 0.20 y 0.40 son medios, y sobre 0.40 son considerados altos. Implicando que el progreso genético vía selección se realizará muy lentamente; la heredabilidad es un parámetro sumamente importante porque determina la proporción en que una característica medida en una población de progenitores puede ser transmitida a la descendencia de estos, y poder predecir de esta manera la magnitud del mejoramiento genético que se puede obtener por selección y por lo tanto decidir 
qué sistema de mejoramiento es más adecuado para un rasgo en particular; permitiendo estimar el valor aditivo de un animal (valor de cría) a partir de mediciones de producción del individuo o de sus parientes (Castellaro et al., 2015). Finalmente, en los ovinos, los valores por tipo de carácter se clasifican en los reproductivos de baja heredabilidad (0.01-0.2), en los productivos (cantidad) de media heredabilidad (0.2-0.4) y en los de calidad (carne, leche, lana) con media-alta heredabilidad $>0.4$, con moderada, media y alta posibilidad de ganancia genética por medio de la selección, respectivamente (Ferrer, 2017).

\section{GANADERÍA OVINA EN COLOMBIA}

En Colombia se concentra un inventario ovino de 1'578.684 cabezas, donde la mayoría de la población ovina se encuentra hacia el norte del país en los departamentos de la región Caribe con el $72.58 \%$, los cuales en orden de importancia son: La Guajira, Magdalena, Cesar y Córdoba $(669.765,171.424$, 125.244 y 111.743 semovientes respectivamente), con condiciones agroecológicas de trópico bajo similares; mientras que en la Región Andina con el 18.62\%, son los departamentos de Boyacá y Santander los más relevantes (105.937 y 51.849 respectivamente), con características climatológicas de trópico alto. Sin embargo, en la región natural de la Orinoquía con el $4.2 \%$ de población ovina, zona de tradición en ganadería bovina, está el departamento del Meta (principalmente los municipios del sur), ubicado en el noveno lugar con 35.380 cabezas, antes de otros departamentos con vocación ovinocultora de tradición en Cundinamarca (ICA, 2018).

Según Camargo, (2016), la población ovina en trópico alto se distribuye entre razas como Romney Marsh, Hampshire Down, Corriedale, Criolla (Mora Colombiana y Manchada Paramuna), Suffolk, Dorset y cruces entre las mismas (mestizas); así mismo para el trópico bajo, criolla (ovino de pelo colombiano o camuro - líneas Sudán, Etiope o Abisinio), Katahdin, Pelibuey y Persa Cabeza Negra principalmente. Sin embargo, en el último quinquenio, se han introducido otra serie de razas, buscando brindar una mayor alternativa para la producción de carne principalmente, para mejorar habilidad materna (producción lechera y prolificidad), 
ganancia de peso y precocidad; como lo son la Dorper, White Dorper, Santa Inés, Black Belly, Charollaise, Cheviot, Texel, Ile de France, East Fresian y Romanov, entre otras (Barrios, 2018). La producción ovina en Colombia se ha caracterizado por un bajo uso de insumos y nivel tecnológico en todas las áreas productivas, y generalmente, está asociada a sistemas de producción tradicionales y artesanales, los cuales atienden principalmente el consumo interno de las granjas y el comercio local, por lo que son poco importantes en su aporte al producto interno bruto (PIB), pero tienen gran impacto en la economía y alimentación campesina (Espinal et al., 2006).

Es de resaltar, que Colombia no cuenta con la información pertinente para tener un conocimiento suficiente de sus niveles de consumo, producción, importaciones, exportaciones o precios. La poca información que existe no es sistemática ni se sustenta en métodos o estudios rigurosos, siendo datos aislados (Rúa y Pabón, 2015). No obstante, la encuesta de sacrificio de ganado realizada por el (DANE, 2018), reportó un aumento del sacrificio de ovinos del $47.7 \%$ entre el último trimestre 2017 y el mismo periodo del 2018, pasando de 9.603 cabezas a 14.184 , respectivamente, con un crecimiento en la producción de carne en canal de $34.5 \%$ (179 a 241 Ton); aunque el peso promedio a sacrificio disminuyó en 10.3\% (de 38 $\mathrm{kg}$ a $34.1 \mathrm{~kg}$ ), pero el rendimiento en canal aumentó en 1.5\%. Del volumen de carne producido, el $89.8 \%$ se destinó a plazas y famas, el $8.7 \%$ a supermercados y el $1.6 \%$ a mercado institucional.

El auge de la industria ovina en Colombia, ha generado impacto desde la percepción general de la producción ganadera en el país, por las potencialidades de la cría de ovinos sobre la posibilidad productiva per se y un aparente mayor consumo; la tendencia sin embargo, no ha generado el impacto esperado por restricciones desde la institucionalidad en temas álgidos como el sacrificio en lugares y zonas establecidas por su impacto comercial, y por la escasa cultura de consumo nacional de carne ovina, con excepción de las zonas productoras por tradición (Departamentos de la Guajira, Santander, Boyacá entre otros) (Vega, 2017). En la actualidad, en Colombia, son pocas las investigaciones desarrolladas en el sector 
ovino; aunque en la literatura se encuentran reportes de algunos trabajos realizados por grupos de investigación en diferentes instituciones, presentando productos relacionados en las áreas de recursos genéticos, alimentación y nutrición. Los estudios generalizados de la diversidad genética de ovinos de pelo, brindarán información relevante para su manejo eficiente, con el fin de generar alternativas económicas para proteger la seguridad alimentaria y la competitividad del sector a nivel nacional e internacional generando ventajas competitivas (Montes et al., 2016). El auge de la producción ovina en Colombia, requiere el acompañamiento integral de todos los actores (gubernamentales y no gubernamentales) que de una u otra forma puedan contribuir con el posicionamiento de la actividad; el modelo actual de manejo de las explotaciones ovinas en Colombia necesita la identificación de aspectos claves para la construcción coherente y propia, de modelos de buenas prácticas ganaderas (BPG) para ovinos, que respondan a la diversidad en formas y estilos con que la producción ha evolucionado desde la llegada misma de los ovinos a partir de la conquista (Vega y García, 2011).

\section{BIOTIPOS Y RAZAS DE GANADO OVINO EN COLOMBIA}

Existen básicamente dos tipos de ovejas, biotipo de lana y de pelo. Las ovejas de pelo no requieren esquila y normalmente se ubican en los terrenos cálidos 0 templados, pues la fibra que se acumula en su dorso, se cae por sí misma (frágil y delgada) y se denomina "lanugo". Las ovejas en este tipo de clima han permanecido sin esquemas de manejo y se han mantenido con problemas severos de consanguinidad, expresado en deficientes índices de producción (camuro u ovino de pelo colombiano), aunque se mantienen altos niveles de resistencia, adaptabilidad y prolificidad. Las ovejas de lana se han usado únicamente para la industria artesanal, pero actualmente se han reorientado los objetivos de la cría hacia la carne, introduciendo genética superior y forjando una sólida base genética; de hecho, las razas cárnicas más difundidas en el mundo tienen cobertura de lana y son de origen europeo, ya que soportan fuertes condiciones ambientales propias de estos países que tienen bajas temperaturas (Barrios, 2018). La raza ovina más apropiada depende de las condiciones ambientales, la intensidad de manejo 
deseada por el productor y las preferencias personales, y generalmente son clasificadas de acuerdo a sus recursos o bondades. Para la producción intensiva de ovejas, puede ser necesario usar tres o más razas para desarrollar un rebaño de ovejas que muestre niveles aceptables de rasgos deseables. Las ganaderías intensivas deben ser capaces de mantenerse activas durante todo el año, producir grandes lotes de corderos, alcanzar la madurez sexual a una edad temprana y crecer rápidamente (Mathis y Ross, 2005). Las razas de lana fina pueden soportar el calor (baja humedad), el frío y la sequía, y producir satisfactoriamente en condiciones difíciles, por lo cual tienen mayor probabilidad independientemente de las condiciones agroecológicas. Algunas de las razas de lana para fines cárnicos son muy productivas cuando el suministro de alimento es amplio, y su época de reproducción es más restringida que la de las ovejas de lana fina (Castellaro, 2016; Rúa y Pabón, 2015; Partida et al., 2013). Sin embargo, al momento de adquirir ejemplares puros, esquematizar los cruces y seleccionar vientres o reemplazos, se debe determinar la línea (materna o paterna) o la bondad de la raza con respecto al objetivo propuesto (Ferrer, 2017), en la Tabla 3 se describen las evaluaciones de las razas para rusticidad, tamaño a la madurez, tasa de crecimiento y prolificidad son subjetivas, variando en diferentes grados, suponiendo que todas las razas son evaluadas en un ambiente común. Las razas ovinas de pelo se caracterizan por caminar grandes distancias para obtener su alimento, mejor almacenamiento de energía, mayor prolificidad no estacional y ser la opción más rentable para las ganaderías del trópico bajo por el efecto de la humedad en la termorregulación (Cordova et al., 2014).

La raza ovina más apropiada depende de las condiciones ambientales, la intensidad de manejo deseada por el productor y las preferencias personales, y generalmente son clasificadas de acuerdo a sus recursos o bondades. Para la producción intensiva de ovejas, puede ser necesario usar tres o más razas para desarrollar un rebaño de ovejas que muestre niveles aceptables de rasgos deseables. Las ganaderías intensivas deben ser capaces de mantenerse activas durante todo el año, producir grandes lotes de corderos, alcanzar la madurez sexual a una edad temprana y crecer rápidamente (Mathis \& Ross, 2005). 
Tabla 3. Clasificación de las razas de acuerdo con algunas características en su desempeño zootécnico

\begin{tabular}{|c|c|c|c|c|c|c|c|c|}
\hline Raza & Biotipo & F.Z. & Rust. $^{a}$ & $\begin{array}{c}\text { T. } \\
\text { Mad. }\end{array}$ & $\begin{array}{c}\text { T. } \\
\text { Crec. }\end{array}$ & Prolif. $^{b}$ & $\begin{array}{c}\text { Est. } \\
\text { Repro. }^{c}\end{array}$ & Línea \\
\hline Black beilly & Pelo & Carne & $A$ & $P$ & $M$ & $A+$ & C & LM \\
\hline Corriedale & Lana & Lana & A & MD & $M_{+}$ & $M+$ & C & LP \\
\hline cheviot & Lana & Carne & M+ & $\mathrm{P}+$ & $B+$ & M & C & LP \\
\hline Charolais & Lana & Carne & B & MD & $A+$ & B & C & LP \\
\hline Dorper & Lana & Carne & A & MD & A & B & ME & LP \\
\hline Dorset & Lana & Carne & $M-$ & MD & $M$ & $M-$ & L & LP \\
\hline $\begin{array}{c}\text { East } \\
\text { Friesian }\end{array}$ & Lana & Leche & $\mathrm{B}+$ & $\mathrm{P}$ & $M$ & M & ME & LM \\
\hline $\begin{array}{l}\text { Hampshire } \\
\text { Down }\end{array}$ & Lana & Carne & $M-$ & G & $A$ & M & ME & LP \\
\hline $\begin{array}{l}\text { lle de } \\
\text { France }\end{array}$ & Lana & Carne & $\mathrm{M}_{+}$ & MD & A & M & $\mathrm{ME}$ & LP \\
\hline Katahdin & Pelo & Carne & A & MD & $A$ & M & $\mathrm{ME}$ & LM \\
\hline $\begin{array}{c}\text { Merino } \\
\text { Ramboulliet }\end{array}$ & Lana & Lana & A & G- & $M_{+}$ & M- & $\mathrm{L}$ & LP \\
\hline Pelibuey & Pelo & Carne & A & MD+ & $M_{+}$ & A- & C & LM \\
\hline $\begin{array}{c}\text { Romney } \\
\text { marsh }\end{array}$ & Lana & Lana & M- & $\mathrm{MD}+$ & $M$ & B & C & LP \\
\hline Romanov & Lana & Carne & A & $\mathrm{P}+$ & $\mathrm{B}+$ & $A+$ & L & LM \\
\hline Santa Inés, & Pelo & Carne & $A+$ & MD+ & $\mathrm{M}$ & $A$ & C & LM \\
\hline Suffolk, & Lana & Carne & B & $G$ & $A+$ & $M_{+}$ & $\mathrm{ME}$ & LP \\
\hline Texel & Lana & Carne & $M$ & $\mathrm{MD}+$ & $M_{+}$ & $M_{+}$ & ME & LP \\
\hline $\begin{array}{l}\text { Dorper } \\
\text { Blanco }\end{array}$ & & Carne & $A+$ & MD & A & M & ME & LP \\
\hline
\end{tabular}

Las razas de lana fina pueden soportar el calor (baja humedad), el frío y la sequía, y producir satisfactoriamente en condiciones difíciles, por lo cual tienen mayor probabilidad de reproducción independientemente de las condiciones agroecológicas. Algunas de las razas de lana para fines cárnicos son muy productivas cuando el suministro de alimento es amplio, y su época de reproducción es más restringida que la de las ovejas de lana fina (Castellaro, 2016; Rúa y Pabón, 
2015; Partida et al., 2013). Sin embargo, al momento de adquirir ejemplares puros, esquematizar los cruces y seleccionar vientres o reemplazos, se debe determinar la línea (materna o paterna) o la bondad de la raza con respecto al objetivo propuesto (Ferrer, 2017). Las razas ovinas de pelo se caracterizan por caminar grandes distancias para obtener su alimento, mejor almacenamiento de energía, mayor prolificidad no estacional y ser la opción más rentable para las ganaderías del trópico bajo por el efecto de la humedad en la termorregulación (Cordova et al., 2014).

\section{Sistemas de producción ovina en Colombia}

En el sistema intensivo los animales reciben toda la alimentación en los comederos, viven al aire libre o confinados, en un área adecuada para el tamaño del rebaño, es el indicado para criar animales especiales para la producción de reproductores, la alimentación es abundante en la propiedad y cuentan con mano de obra especializada; en la estabulación, los animales son confinados durante toda su vida a corrales donde cuentan con los cuidados necesarios como sombra, comederos y bebederos automáticos. En esta categoría existen unidades especiales para cada etapa fisiológica, donde los animales son atendidos de acuerdo con sus necesidades específicas de sexo, edad y peso. En el sistema de producción semiextensivo, los animales pastorean durante el día y reciben una suplementación en el comedero, en el final de la tarde; están en ausencia de predadores, son suficientes algunos árboles para servir de abrigo, es el indicado para criar animales de tipo mixto para la producción de lana y carne, o leche y carne. En el sistema extensivo, la crianza de animales es en gran escala y utilizan pasturas nativas 0 artificiales como fuente principal de alimentos, las condiciones sanitarias son desconocidas; aquí no se proporcionan alimento adicional, y solo reciben sales minerales como suplementos (Vega y García, 2011).

En Colombia se pueden describir los tres sistemas de producción (Tabla 4), entre los que se identifican los sistemas de producción intensivo, basados en razas mejoradas de reciente introducción, ubicados en zonas cercanas a los centros de consumo y que utilizan un nivel tecnológico medio alto, con tamaño de 
explotaciones intermedio, donde la actividad principal está dirigida a la producción de leche, productos procesados, para consumo local y para distribución regional, genética (reproductores) y en menor proporción la producción de carne (Vivas, 2013).

Tabla 4. Características de los sistemas de producción ovina en Colombia

\begin{tabular}{|c|c|c|c|}
\hline Sistema & Ubicación & Características & Biotipos \\
\hline Intensivos & $\begin{array}{c}\text { Cerca de grandes } \\
\text { capitales }\end{array}$ & $\begin{array}{l}\text { Nivel tecnológico: Medio alto. } \\
\text { Tamaño de las Explotaciones: } \\
\text { pequeño } 10-40 \text { animales } \\
\text { Productos: Carne para } \\
\text { supermercados y exportación }\end{array}$ & $\begin{array}{l}\text { Hampshire, } \\
\text { Romney Marsh y } \\
\text { Ovinos de Pelo }\end{array}$ \\
\hline $\begin{array}{c}\text { Semi } \\
\text { extensivos }\end{array}$ & $\begin{array}{c}\text { Llanos orientales, } \\
\text { Tolima, } \\
\text { Santanderes }\end{array}$ & $\begin{array}{l}\text { Nivel tecnológico: Medio. } \\
\text { Productos: Carne para auto- } \\
\text { consumo, supermercados y pie de } \\
\text { cría }\end{array}$ & $\begin{array}{l}\text { Ovinos de Pelo } \\
\text { mestizos y } \\
\text { cruzados con } \\
\text { razas } \\
\text { introducidas. }\end{array}$ \\
\hline Extensivos & $\begin{array}{l}\text { Zonas de } \\
\text { Economía } \\
\text { Campesina } \\
\text { (Boyacá, } \\
\text { Cundinamarca, } \\
\text { Guajira, } \\
\text { Santanderes, } \\
\text { Nariño y Llanos } \\
\text { Orientales). }\end{array}$ & $\begin{array}{c}\text { Zonas Agroecológicas: Trópico Alto } \\
\text { (ovino de lana) y Trópico Medio y } \\
\text { Bajo (Ovino de Pelo) } \\
\text { Nivel Tecnológico: Bajo. } \\
\text { Tamaño de las explotaciones: muy } \\
\text { variable, economía campesina (2-20 } \\
\text { animales), hasta grandes } \\
\text { poblaciones trashumantes (50-300 } \\
\text { animales). }\end{array}$ & $\begin{array}{l}\text { Mestizos de razas } \\
\text { de reciente } \\
\text { introducción y } \\
\text { biotipos criollos }\end{array}$ \\
\hline
\end{tabular}

Fuente: Martinez et al., (2009)

El sistema de producción extensivo se caracteriza por utilizar biotipos criollos o sus cruces con razas mejoradas, se ubica en regiones de baja aptitud agrícola, zonas montañosas altas en la región andina, y zonas planas áridas de Santander, Cesar y la Guajira, donde el nivel tecnológico utilizado es muy bajo, limitado a las necesidades implantadas por la economía campesina y de algunas comunidades indígenas y en algunos casos ubicados en sistemas de explotación mixtos con bovinos, pero igualmente en sistemas extensivos y extractivos. En el caso del ovino de lana la actividad principalmente está dirigida a la producción de carne para el consumo local y lana para la producción de artesanías y en el caso de los sistemas de producción en trópico bajo se limita a la producción de carne y de pie de cría para otras explotaciones, se da principalmente en zonas de la costa norte donde se trabaja con un tipo de ovino criollo de pelo (Vivas, 2013). 
Se podría diferenciar un sistema de producción semi-extensiva, ligada principalmente a sistemas de explotación mixta con bovinos, en algunas regiones de la costa norte y en los llanos orientales de Colombia, regiones de predominancia ganadera. En este tipo de explotación, la finalidad es complementar los dos sistemas, utilizando los ovinos como una alternativa para el control de maleza y para utilizar zonas de las granjas que no pueden ser utilizadas por bovinos. Los productos que se generan, son utilizados en la misma finca y ocasionalmente se utilizan para la venta como pie de cría (Vivas, 2013).

Las producciones en zonas de la costa norte utilizan ovinos criollos de pelo, conocidos como camuros, y se cuenta con grandes rebaños, explotando conjuntamente ovinos y caprinos en sistemas de producción extensivos, con trashumancia y con un manejo muy precario de condiciones sanitarias, reproductivas y genéticas. También existen explotaciones mixtas ovinas de lana y caprinas en las regiones áridas de trópico medio de Santander, donde tienen un nivel tecnológico algo más desarrollado, pero atienden el mercado local y el autoconsumo (Castellanos et al., 2010). Otra región que se ha vuelto importante en los últimos años para la explotación ovina de pelo está comprendida por los departamentos de Tolima, Huila y los Llanos Orientales, principalmente en Meta y Casanare, donde se han incluido en los sistemas de producción de bovina de carne, así como en otras actividades agrícolas como los cultivos de palma, donde se utilizan para el control de arvenses. La producción en este tipo de sistemas mixtos se usa principalmente para el consumo interno de las granjas y para el comercio local. En el Valle del Cauca se utilizan ovejas de pelo en sistemas integrados a la agricultura tecnificada de la caña de azúcar, para el control de arvenses y producción de carne (Martínez et al., 2009).

\section{Nutrición y alimentación del ganado ovino}

El adecuado consumo de materia seca, energía y proteína, son fundamentales para mantener una buena nutrición en el rebaño, que permitirá maximizar el nivel productivo y corregir cualquier desbalance nutricional que afecte el ganado (Castellaro, 2016). Los ovinos al ser rumiantes, poseen un conducto gastrointestinal 
con cierto grado de especialización y variaciones anatómicas resultado de la evolución y la selección del alimento (Velázquez et al., 2017). Se alimentan de pastos, pajas, arbustos, leguminosas o forrajes de bajo valor nutritivo y difícil digestión, aprovechando solo una parte de los carbohidratos estructurales por acción enzimática de los microorganismos que viven en sus divertículos estomacales; sin embargo, los fuertes vínculos entre la celulosa, hemicelulosa y lignina impiden la accesibilidad total de las enzimas microbianas del rumen, bloqueando cantidades significativas de energía para el animal, lo que ocasiona una disminución en su producción (Velázquez et al., 2017). Estos alimentos son expuestos a procesos fermentativos efectuados por los microorganismos que se encuentran en parte del sistema digestivo, existiendo un uso eficiente de los nutrientes contenidos en los distintos ingredientes de la dieta, en especial aquellos que aparentemente tienen un bajo aporte nutricional. Los rumiantes por si solos no son capaces de utilizar los forrajes; esa función es propia de los microorganismos presentes en el rumen (Castellaro et al., 2015). Sin embargo, el cordero nace con su aparato digestivo adaptado a una dieta láctea, propia de un no-rumiante. Por esta razón los divertículos estomacales (retículo, rumen y omaso), no funcionales, son pequeños al nacimiento (Tabla 5) y el cierre de la gotera esofágica desvía la leche directamente al abomaso. La gotera esofágica es una estructura anatómica que conecta el esófago con el abomaso, donde bajo condiciones normales de alimentación, los divertículos estomacales se van desarrollando mientras se hacen funcionales (Relling y Matiolli, 2003).

Tabla 5. Capacidad relativa de divertículos estomacales del cordero en función de la edad, (\%) de capacidad gástrica total.

\begin{tabular}{cccc}
\hline Edad & Retículo-Rumen \% & Omaso \% & Abomaso \% \\
\hline Neonato & 31 & 7 & $62(0.5 \mathrm{~L})$ \\
3-4 Semanas & 63 & 4 & $33(0.7 \mathrm{~L})$ \\
7-8 Semanas & 77 & 4 & $19(1 \mathrm{~L})$ \\
$11-12$ Semanas & 71 & 7 & $22(2 \mathrm{~L})$ \\
Adulto & 73 & 9 & $18(3 \mathrm{~L})$ \\
\hline
\end{tabular}

Fuente: Adaptado de Relling y Matiolli, (2003); Parish et al., (2017); Redondo, (2003). 
El desarrollo de los divertículos estomacales suele dividirse en tres períodos; entre el nacimiento y las cuatro semanas de vida (Figura 1): El animal es "lactante", posee sólo capacidad de digerir leche y depende de la absorción intestinal de glucosa para mantener un valor de glucemia, que es semejante al de un no rumiante (alrededor de $1 \mathrm{~g} / \mathrm{L}$ ); entre las tres y las ocho semanas de vida: Es un "período de transición" durante el cual el animal comienza a ingerir pequeñas cantidades de alimento sólido y se van desarrollando gradualmente los divertículos estomacales. Los valores de glucemia comienzan a disminuir mientras aumenta la concentración plasmática de ácidos grasos volátiles (AGV), especialmente acetato (C2), propionato (C3) y butirato (C4); a partir de las ocho semanas de vida: Los divertículos estomacales están bien desarrollados y permiten una digestión fermentativa propia del "rumiante adulto" (Relling y Matiolli, 2003; Godfrey et al., 1993).
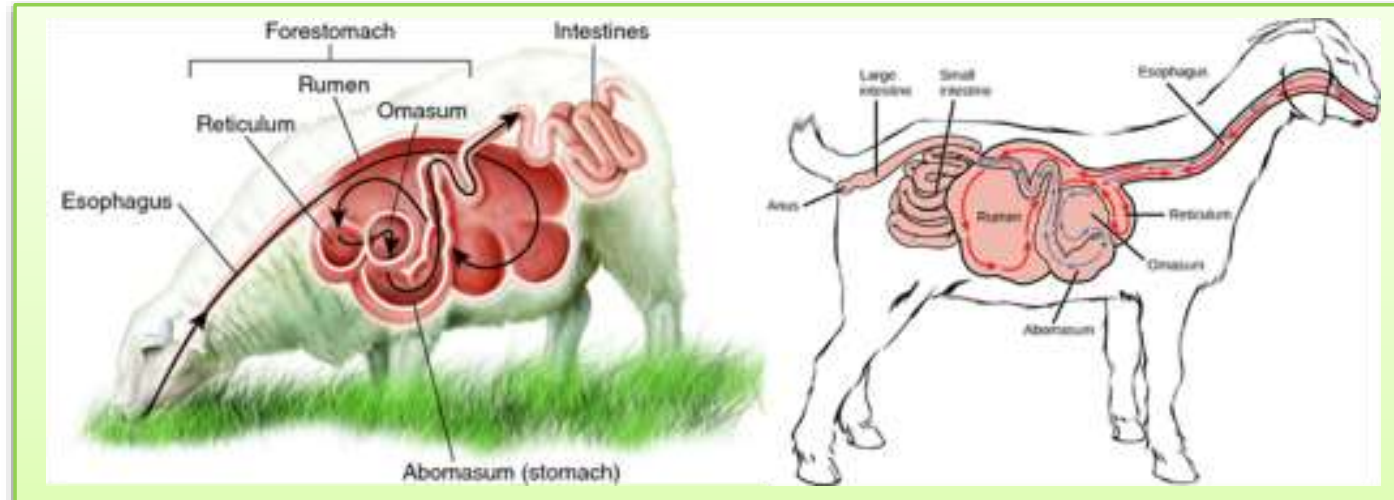

Figura 1. Estructura y fisiología digestiva en los ovinos Fuente: Godfrey et al., (1993); Parish et al., (2017)

El aparato masticador de los ovinos está conformado por las mandíbulas, dientes y músculos que intervienen en la masticación, la cual es una acción previa a la digestión, permitiendo la reducción de los materiales vegetales hasta un tamaño adecuado para los microorganismos del rumen e intestinos. El esófago es un tubo que desemboca en el estómago, el cual posee cuatro cavidades: el retículo, el rumen, el omaso y el abomaso, los tres primeros son conocidos como preestómagos o divertículos estomacales, y poseen una mucosa aglandular (no excretan jugos gástricos), el abomaso es una estructura glandular, el retículo y el abomaso se encuentran unidos por un pliegue denominado retículo-ruminal, que 
conforma una cuba de fermentación. El intestino está caracterizado por su longitud y por su disposición de una cámara distal de fermentación; el intestino delgado posee una mucosa con presencia de vellosidades a diferencia del intestino grueso el cual carece de éstas, las funciones homeostáticas del intestino grueso incluyen el mantenimiento del equilibrio entre los electrolitos y los fluidos, además de ser el almacén temporal de las heces hasta su eliminación (Godfrey et al., (1993); Redondo, 2003; Velázquez et al., 2017).

\section{REQUERIMIENTOS NUTRICIONALES Y ETAPAS PRODUCTIVAS}

Las necesidades nutritivas o requerimientos nutricionales de los ovinos se refieren a su demanda diaria en agua, energía, proteínas, minerales y vitaminas, para mantener un adecuado crecimiento, producción y reproducción. Sin embargo, estas necesidades varían de acuerdo al sistema de producción, al estado fisiológico (monta, fases de la gestación, lactancia, mantenimiento), sexo, edad y peso vivo de cada animal (Romero y Bravo, 2012) (Tabla 6.). En cada una de estas etapas debe proporcionarse una alimentación adecuada para obtener los mejores resultados productivos y económicos. No obstante, los requerimientos nutricionales en ovejas son menores durante la etapa abierta (hembra vacía) y las primeras semanas de la gestación, y serán más elevados al final de la preñez y durante la lactancia, sobre todo cuando se presentan partos multíparos; así mismo en el periodo de crecimiento de los corderos (Partida et al., 2013). Por ejemplo, para alimentar corderos para alta ganancia de peso, se emplean dietas altas en granos, por el contrario, para alimentar ovejas adultas en mantenimiento se emplean dietas con alto contenido de forraje. En cualquier caso, lo importante es hacer la combinación apropiada de alimentos para asegurar y cubrir las necesidades (Rúa y Pabón, 2015). Las ovejas en mantenimiento (vacías) necesitan comer menos proteína y energía que las ovejas en el último tercio de gestación o en lactancia. La cantidad de forraje verde que debe consumir un ovino, se estima con base a un $10 \%$ de su peso vivo; y en términos de forraje seco, se estima con base a un 2.5 a $4 \%$ de su peso (Galaviz et al., 2011). La cantidad de alimento seco que debe comer una oveja en sus diferentes etapas productivas. Las ovejas necesitan comer más alimento y energía durante la 
monta, la gestación y la lactancia. Por lo tanto, se debe planificar la alimentación del rebaño para asegurar que las ovejas coman la cantidad de nutrimentos que necesitan según su etapa productiva y fisiológica (Galaviz et al., 2011).

Tabla 6. Requerimientos nutricionales de los ovinos para diferentes condiciones fisiológicas

\begin{tabular}{ccccccccc}
\hline $\begin{array}{c}\text { Condición } \\
\text { Fisiológica }\end{array}$ & $\begin{array}{c}\text { Peso } \\
\mathbf{K g}\end{array}$ & $\begin{array}{c}\text { GDP } \\
\mathbf{g} / \mathbf{d}\end{array}$ & $\begin{array}{c}\text { Consumo } \\
\text { MS, Kg/d }\end{array}$ & $\begin{array}{c}\text { Consumo } \\
\text { MS, \% PV }\end{array}$ & $\begin{array}{c}\text { TND } \\
\text { Kg/d }\end{array}$ & $\begin{array}{c}\text { EM } \\
\text { Mcal/d }\end{array}$ & $\begin{array}{c}\text { PM } \\
\mathbf{g} / \mathbf{d}\end{array}$ & $\begin{array}{c}\text { PDR } \\
\mathbf{g} / \mathbf{d}\end{array}$ \\
\hline Mantenimiento & 50 & 0 & 0.91 & 1.83 & 0.41 & 1.75 & 47 & 63 \\
$\begin{array}{c}\text { Empadre } \\
\text { Gestante }\end{array}$ & 50 & 23 & 1.01 & 2.01 & 0.53 & 1.92 & 55 & 69 \\
$\begin{array}{c}\text { (Múltiple) } \\
\text { Gestación }\end{array}$ & 50 & 35 & 1.31 & 2.62 & 0.7 & 2.51 & 76 & 90 \\
$\begin{array}{c}\text { (Último tercio) } \\
\text { Lactancia }\end{array}$ & 50 & 183 & 1.41 & 2.81 & 1.12 & 4.03 & 116 & 145 \\
$\begin{array}{c}\text { Reemplazo } \\
\text { (Borregas) }\end{array}$ & 30 & 200 & 1.05 & 3.51 & 0.56 & 2.02 & 92 & 73 \\
$\begin{array}{c}\text { Reemplazo } \\
\text { (Carneros) }\end{array}$ & 40 & 300 & 1.58 & 3.96 & 0.84 & 3.03 & 135 & 109 \\
& 20 & 200 & 0.59 & 2.97 & 0.39 & 1.42 & 78 & 51 \\
$\begin{array}{c}\text { Corderos en } \\
\text { Crecimiento }\end{array}$ & 30 & 300 & 0.88 & 2.93 & 0.58 & 2.1 & 114 & 76 \\
& 40 & 400 & 1.16 & 2.91 & 0.77 & 2.78 & 150 & 100 \\
& 50 & 500 & 1.45 & 2.9 & 0.96 & 3.47 & 186 & 125 \\
\hline
\end{tabular}

GDP: Ganancia Diaria de Peso; g/d: Gramos por día; MS: Materia Seca; Kg/d: Kilogramos por día; PV: Peso Vivo; TND: Nutrientes Digestibles Totales; EM: Energía Metabolizable; PM: Proteína Metabolizable; PDR: Proteína Digestible en Rumen.

Fuente: National Research Council, 2007; Tomado de Galaviz et al., (2011)

\section{PLANES DE ALIMENTACIÓN}

En términos generales, se pueden definir varios períodos críticos en el ciclo biológico de los ovinos respecto a la oferta de forraje a través del año, que coinciden con una mayor demanda de forraje, como lo son: La monta, el último tercio de la gestación, lactancia y destete, donde los requerimientos superan la oferta forrajera de la pradera. Estos períodos críticos pueden ser manejados al ajustar la carga animal del predio, trasladando los excedentes de forraje producidos en época de lluvias y teniendo un sistema forrajero que sea capaz de satisfacer las demandas 
nutricionales de los ovinos (Ej. banco de proteína); sin embargo, para definir las alternativas forrajeras que satisfagan las demandas nutricionales de los animales se requiere de una planificación forrajera predial (Romero y Bravo, 2012).

Se recomienda establecer grupos homogéneos en los que sus condiciones productivas o reproductivas sean similares para identificar sus requerimientos y desarrollar programas específicos de alimentación. Por ejemplo, en el hato reproductor se pueden identificar seis etapas importantes a lo largo del ciclo: periodo seco (ovejas vacías), época de pre-monta (realización del "flushing" o aumento de la suplementación energética para recuperar condición corporal), montas, inicio de la gestación, final de la gestación y lactancia (Rúa y Pabón, 2015). En cada una de estas etapas debe proporcionarse una alimentación adecuada para obtener los mejores resultados productivos y económicos. Los requerimientos nutricionales son menores durante el periodo seco y las primeras semanas de la gestación, y serán más elevados al final de la misma y durante la lactancia, sobre todo cuando se presenten partos multíparos (Partida et al., 2013).

De acuerdo al manejo en los sistemas pastoriles y los requerimientos nutricionales de los ovinos, se debe realizar un análisis forrajero que permita cuantificar la superficie de los recursos forrajeros disponibles por tipo de praderas (nativas, anuales, bianuales, permanentes) y su calidad (buena, mala, regular) con base en los recursos forrajeros presentes en cada una de ellas; disponer de un inventario animal, que indique claramente el número de animales por categoría (edad) y su estado fisiológico, y determinar los requerimientos nutricionales del rebaño por categoría animal. Siendo estos tres elementos los que permiten determinar la carga ganadera del predio, en función de la producción y calidad del forraje, de acuerdo a su aporte de proteína y energía metabolizable (Galaviz et al., 2011; Romero, 2010; Vega y García, 2011). Además, para poder determinar la calidad de las dietas y los complementos alimenticios que se deben proporcionar, se requiere conocer la cantidad de forraje consumido durante el pastoreo y la calidad de estos forrajes (Bueno et al., 2017). 
Finalmente, la tendencia creciente del costo de los cereales, a causa de la demanda para otros usos distintos a la alimentación animal (biodiesel y seguridad alimentaria), genera incrementos en los precios de los concentrados más o menos pronunciados según la situación política y económica de cada país. En esta coyuntura, se deben plantear alternativas viables para la diversificación de los sistemas de producción ovina, en cuyo proceso se respete el medio ambiente, se disminuyan los costos de producción, se aprovechen sustentablemente los recursos forrajeros y se provea al mercado un producto que logre satisfacer las exigencias del consumidor actual (Joy et al., 2016).

\section{Pastoreo}

Para lograr la máxima producción ovina en pastoreo, de una forma sostenida, se requiere implementar los cuatro principios básicos para el manejo; una carga animal adecuada, el tipo de animal adecuado, realización del pastoreo en la época apropiada (días descanso y días de ocupación) y la distribución adecuada del pastoreo (divisiones y carga animal). La carga animal es el número de unidades animales que pastorea una superficie determinada en un cierto período de tiempo, donde la unidad animal equivale al consumo de forraje (respecto a la materia seca) que tiene el animal en un día y que equivale al $2.5-4 \%$ de su peso vivo, haciendo énfasis a la capacidad de carga, definida como el número de unidades animales que un pastizal puede sostener sin causar daño a la vegetación (Esqueda y Gutierrez, 2009).

Para el caso de los ovinos (Tabla 7) se han estimado medidas específicas de equivalencia, denominadas unidades equivalentes ovinas (UEO) (Rúa y Pabón, 2015). Se hace necesario estimar la cantidad de forraje que van a consumir los animales, para ofertar lo necesario, promoviendo un uso eficiente de los recursos, mediante un análisis comparativo entre los requerimientos y la oferta del forraje, ya sea de praderas, cultivos suplementarios y forraje conservado (SSDB, 2017; Rúa y Pabón, 2015). En la Figura 2, se puede encontrar una herramienta básica para la planificación de sistemas pastoriles, en corto y mediano plazo. 
Tabla 7. Equivalencia de diferentes tipos de ovinos en unidades equivalentes a la unidad animal.

\begin{tabular}{cccccccc}
\hline $\begin{array}{c}\text { Oveja } \\
\text { Con } \\
\text { Cordero } \\
\mathbf{4 5 - 6 5} \mathbf{~ k g}\end{array}$ & $\begin{array}{c}\text { Oveja } \\
\text { sin } \\
\text { Cordero } \\
\mathbf{5 5} \mathbf{~ k g}\end{array}$ & $\begin{array}{c}\text { Borrega } \\
\text { Seca }\end{array}$ & $\begin{array}{c}\text { Borrega } \\
\text { Post- } \\
\text { monta }\end{array}$ & Borrego & Capón & Canillero & Canero \\
\hline $0.7-1.1$ & 0.7 & 0.7 & $0.7-10$ & 0.7 & 0.7 & 1.0 & 0.8 \\
\hline
\end{tabular}

Fuente: Rúa y Pabón, (2015)

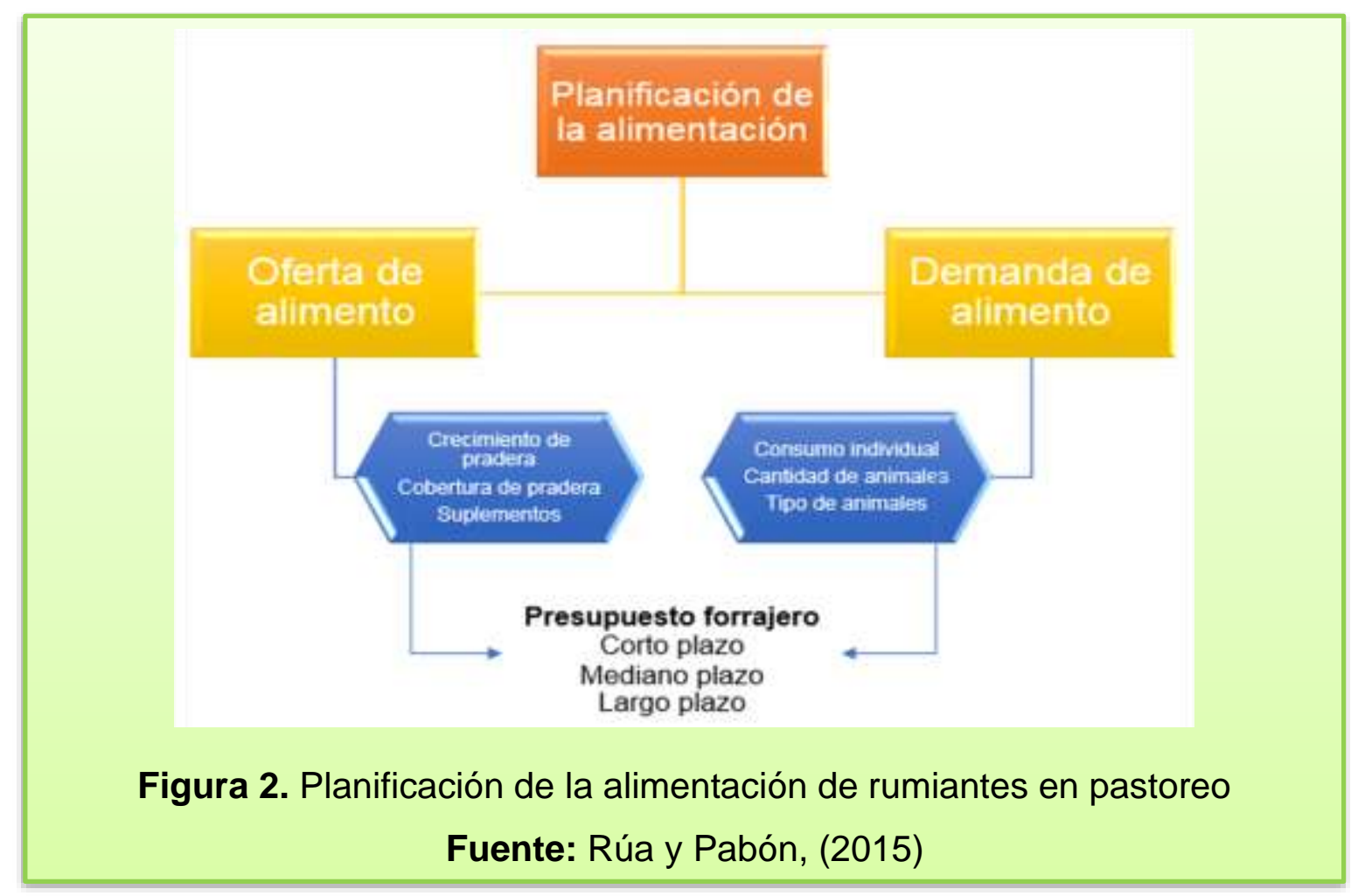

La planificación se hace con respecto al contenido de materia seca del forraje (15$20 \%$ ) y los demás recursos forrajeros disponibles, teniendo en cuenta la edad de cosecha de los mismos (concentración de lignina), las necesidades correspondientes al peso vivo y la unidad equivalente ovino; logrando así establecer los requerimientos diarios en cada lote y estructurar objetivamente en épocas de lluvias y seca, las alternativas para suplementar estratégicamente con granos $u$ otras materias primas (Barrios, 2018). Las pajas y los granos de cereales, en general, son los alimentos que tienen los mayores porcentajes de materia seca y 
por ende un menor contenido de agua. Lo contrario sucede con el pasto fresco, ya sea tierno y/o maduro, donde el porcentaje de materia seca no supera el $30 \%$ (Galaviz et al., 2011).

El contenido celular de los vegetales es rico en proteína, azúcares solubles, grasas, almidones y pectinas, compuestos que son de fácil digestión. No obstante, las células vegetales poseen también una pared que está constituida por carbohidratos estructurales (celulosa y hemicelulosa) y por lignina, lo que corresponde a la fibra detergente neutro (FDN); dentro de esta pared, existe una fracción que es de baja digestibilidad compuesta principalmente por celulosa y lignina, el cual es denominado fibra detergente ácido (FDA). A medida que las plantas maduran, el contenido de pared celular aumenta y disminuye el de los contenidos celulares, lo que hace que la capacidad ingestión y de digestión del material vegetal disminuya, reduciendo su valor nutricional (Romero y Bravo, 2012).

No obstante, la fibra en las dietas de rumiantes es muy importante ya que además de ser una fuente de carbohidratos que producen energía, mantienen el funcionamiento del rumen en condiciones adecuadas. La fibra promueve la producción de saliva, lo cual ayuda a la mantención del pH del rumen y su adecuada motilidad, manteniendo estable el proceso fermentativo, lo que se traduce en un adecuado proceso de digestión de los nutrientes (Castellaro et al., 2015).

\section{Semi estabulación}

Es un método de alimentación que le permite al ganadero, durante cierto tiempo, en el día, entregarles una ración adicional de alimento a los animales, especialmente en la época seca que los forrajes son más toscos y tienen menos nutrientes. Esta se ha convertido en una alternativa para tecnificar los rebaños, disminuir los costos, mejorar la alimentación y aumentar la productividad (Rúa y Pabón, 2015). Para un adecuado plan de alimentación en semi-estabulación es necesario contar con alimento de buena calidad, praderas verdes, heno y ensilaje, entre otros. En caso de no contar con forrajes o praderas de buena calidad, es indispensable considerar la suplementación energético-proteica de los ovinos (Romero y Bravo, 2012). En 
este sistema se cuentan con praderas de mediana y alta calidad en monocultivo con pastos introducidos (Panicum spp y Brachiaria spp), así como áreas para corte y acarreo de material vegetal (bancos de proteína y bancos energéticos), con el fin de suministrar alimentos forrajeros en el encierro (aprisco) (Castellaro et al., 2015)).

\section{Estabulación}

Antes de iniciar con un esquema de alimentación en estabulación se hace necesario tener en cuenta que esto tiene un costo importante, se debe realizar en el menor tiempo posible (engorde), la mayoría de los alimentos son adquiridos fuera del establecimiento y deben ser de buena calidad, y se debe disponer de un conocimiento mínimo para su manejo, porque es una actividad relativamente nueva para muchos productores (Giraudo et al., 2014).

Los forrajes de corte pueden ser utilizados eficientemente en la alimentación ovina cuando se consideran sus limitaciones y se corrigen tomando las medidas necesarias de manejo y balanceo de las dietas. Además, pueden generar carne magra de mejor aceptación por el consumidor o permitir finalizar los corderos con pesos superiores sin demasiado engrasamiento (Huerta, 2016). Las raciones manejadas en estabulación, generalmente están compuestas por alimentos concentrados energéticos (granos), proteicos (tortas de girasol o soya) y fibra (henos o pellet de gramíneas). Los alimentos balanceados comerciales combinan todos estos componentes; en la actualidad, también se dispone de una oferta de buena calidad de alimentos balanceados formulados especialmente para estas especies, que pocos años atrás era muy limitada. Como aporte de fibra también se puede, en los lugares donde se lo disponga, emplear pasturas de buena calidad (Giraudo et al., 2014).

\section{Estrategias de alimentación por etapa fisiológica}

El número de corderos nacidos cada temporada es un factor decisivo en la productividad de la ganadería ovina, donde la alimentación cumple un rol fundamental, puesto que un rebaño en buen estado nutricional (con una condición corporal adecuada), producirá un mayor número de corderos, que además tendrán 
mejores pesos al destete y mayor probabilidad de sobrevivencia (Martínez, 2012). Así mismo, el uso de concentrados y forrajes de alta calidad en el periodo de lactancia (al lado de la madre) de los corderos, como alternativa alimentaria, permite un desarrollo precoz del rumen, ganancias de peso mayores $y$, por ende, mayor precocidad al destete (Banchero et al., 2006). Dentro de estos mecanismos encontramos el "flushing" o golpe alimenticio o acondicionamiento, "creep feeding" o suplementación de paso y "creep grazing" o pastoreo de paso (Partida et al., 2013). Los cuales se describen así:

- Flushing: Consiste en incrementar el plano nutricional (nivel de energía, proteína y otros nutrientes) que reciben las ovejas en el periodo de pre-monta y monta. Los efectos fisiológicos (fundamentalmente hormonales) de esta práctica desembocan en un aumento de la tasa de ovulación, y por lo tanto de la prolificidad (número de animales nacidos por parto) (Martínez, 2012).

- Creep feeding: Es donde el cordero recibe preferencialmente concentrados, estando al lado de su madre, pero donde ella no puede tener acceso. Posibilitando un desarrollo precoz del rumen. Es recomendable que los corderos se inicien, alrededor de los 7-10 días de nacidos. A pesar de que los corderos no consumirán cantidades significativas de alimento hasta las 3-4 semanas de vida. Estas pequeñas cantidades consumidas de suplemento, a temprana edad, son importantes para establecer tanto la funcionalidad del rumen como el hábito de consumo de suplemento (Banchero et al., 2006).

- Creep grazing: Se conoce como el uso de pasturas para la suplementación preferencial de corderos lactantes, donde el cordero accede o se le suministran pasturas mejoradas de alta calidad, sin que la oveja pueda acceder a ellas. Permitiendo el desarrollo de las papilas ruminales más rápido y siendo más económico que el Creep feeding. El área exclusiva de acceso o suministro de la pastura mejorada a los corderos debe calcularse según la disponibilidad inicial de forraje, la tasa de crecimiento diaria esperada del forraje, utilizando un rango de valores que permitan cierta flexibilidad frente a situaciones no esperadas de reducción del crecimiento de la pastura, consumo de forraje potencial del cordero, establecer un remanente mínimo de altura de corte del 
forraje $(8 \mathrm{a} 10 \mathrm{~cm})$ para favorecer la selectividad por parte del cordero, el valor nutritivo de la dieta cosechada por los corderos, las metas establecidas de ganancia de peso de los corderos y las variaciones de los requerimientos en el consumo de forraje a lo largo del proceso de crecimiento del cordero (Allen, 1993).

\section{Manejo de praderas para ganado ovino}

La producción de forraje depende de factores como suelo y clima, y de componentes biológicos como plantas y animales, que interactúan en el tiempo y el espacio, los cuales son modificados por el hombre a través del manejo (Franco et al., 2007). La primera etapa para incrementar la producción de forraje es mejorar la fertilidad del suelo, con el fin de asegurar que los nutrientes esenciales estén presentes en la cantidad y oportunidad requerida para ser absorbidos por las plantas, con mínimas pérdidas que contaminen el medio ambiente (González y Tapia, 2017). Los elementos principales que limitan el establecimiento y mantenimiento de las especies forrajeras en el trópico son nitrógeno, fósforo y potasio $(N, P, K)$ y también calcio, magnesio y azufre (Ca, Mg y S) (Rúa y Pabón, 2015).

El primer pastoreo o cosecha de los pastos y forrajes, se debe realizar entre los 90 a 120 días después de la siembra, permitiendo el afianzamiento de la raíz y un desarrollo foliar óptimo para la actividad fotosintética, evitando el arrancamiento en el momento de la aprehensión por parte de los animales; iniciando con animales jóvenes para no permitir un pastoreo tan exhaustivo o la realización del corte entre los 20 a $30 \mathrm{~cm}$, respecto al borde del suelo (Castellanos et al., 2010). El periodo de ocupación de la pradera para cada especie forrajera varía con respecto a la productividad de la misma determinada mediante un aforo $\left(\mathrm{kg} / \mathrm{m}^{2}\right)$, tipo de animales, época del pastoreo, condiciones sanitarias de los semovientes y tiempo de descanso de la pradera; oscilando entre 1 y máximo 3 días, evitando diferencias fenológicas de la pradera, lo cual representaría el debilitamiento de la misma (Romero, 2010). Igualmente, el periodo o días de descanso en praderas, como se expresó anteriormente, de acuerdo a las condiciones agroecológicas, exigencias nutricionales del forraje y rendimiento por unidad de área, en ovinos para trópico 
bajo se maneja entre 30 y 35 días; para forrajes de corte y acarreo está entre 45 y 60 días (García y Pérez, 2017).

Para el mantenimiento de una pradera (monocultivo, policultivo y multiestrato), banco de proteína o banco energético, se deben tener en cuenta los mismos aspectos para su establecimiento, como son una fertilización (edáfica o foliar), distribuida a lo largo del año, control integral de arvenses y plagas (mecánico o químico), sistema de riego o balance hídrico. De la misma manera, la renovación de la misma, ya sea para oxigenar el suelo (arado de cincel) con el fin de mejorar la retención de agua y porosidad o para resiembra (áreas de baja densidad vegetal), se hace en el momento de la salida de los animales, o en su defecto, en un tiempo no mayor a 5 días del pastoreo, este aspecto se determina de acuerdo al periodo de ocupación y las características de la pradera (Franco et al., 2007).

De acuerdo a lo planteado las prácticas culturales consideradas adecuadas durante el establecimiento, serían la adecuación del terreno, preparación del suelo de manera que favorezca la emergencia rápida y uniforme, y un crecimiento vigoroso de los pastos sembrados, siembra usando semilla con buena pureza y potencial de germinación, conocimiento y manejo de los problemas de plagas y enfermedades, aplicación de fertilizantes si el suelo lo necesita para favorecer las especies establecidas y manejo del primer pastoreo, en cuanto a número de animales y días de ocupación es un criterio muy importante, generalmente se requiere de pastoreos ligeros o cortes parciales (Esqueda y Gutierrez, 2009; Franco et al., 2007).

\section{Tipos de pastoreo en ovinocultura}

Los sistemas de pastoreos más usados en la producción ovina son similares a los usados en las otras especies animales. Según Castellaro et al., (2015) y González y Tapia, (2017) se destacan:

- Pastoreo continuo: Se refiere a un sistema extensivo de pastoreo donde el ovino permanece en un mismo potrero durante un tiempo prolongado. Este pastoreo permite a los animales pastorear selectivamente. 
- Pastoreo rotativo o rotacional: Para realizar este tipo de pastoreo, las praderas deben ser divididas en potreros mediante cercos eléctricos y cercos semi permanentes. Los animales se rotan en base a la disponibilidad y la tasa de crecimiento del forraje. Este sistema utiliza eficientemente las praderas al poder controlar una altura deseable, de acuerdo a la especie forrajera y al tipo de animal, de manera que se le permita a la pradera un rebrote y un crecimiento vigoroso antes de ser nuevamente pastoreada.

- Pastoreo diferido: Este sistema de pastoreo consiste en dejar en descanso algunos potreros por ciertos períodos, antes de iniciarse la época seca. Esto con el fin de utilizarlos posteriormente. La práctica de conservar heno o fardos es el mejor ejemplo de este tipo de pastoreo. La desventaja de este sistema es que, para el tiempo en que el ovino utiliza los potreros, el pasto por su excesiva madurez muestra una menor aceptabilidad y valor nutritivo, contribuyendo exclusivamente como una ración de mantenimiento.

- Pastoreo mixto: Sistema de pastoreo en el que se utilizan diferentes especies de animales como ganado bovino, ovino y/o caprino, que pastorean juntos aprovechando el sistema de cosecha y preferencia que cada uno posee. Este tipo de pastoreo es muy utilizado en países como Uruguay, donde se complementa con la utilización de la pradera, puesto que hay preferencias entre ambas especies.

\section{Enfermedades metabólico-nutricionales}

La principal enfermedad en ovinocultura está relacionada con la nutrición, y justamente no proporcionar a los animales dietas que cubran sus necesidades metabólicas en función de su condición productiva. La mayor parte de los rebaños, están subalimentados, y así los animales no pueden responder inmunológicamente a las enfermedades, no tienen buen comportamiento reproductivo, las ovejas producen poca leche y se les mueren los corderos (Tórtora, 2017). Así mismo, los excesos de nutrientes o el mal manejo de las dietas, genera condiciones inadecuadas desencadenadas en desbalances metabólicos e intoxicaciones, (Pezzanite et al., 2010). 
Deficiencia de selenio (Se): La deficiencia de selenio, en asociación con la deficiencia de vitamina $E$, produce la enfermedad conocida como del "músculo blanco" o atrofia muscular. La digestibilidad y absorción del Se en los rumiantes es muy baja, alrededor del $19 \%$ en ovejas.

Intoxicación por cobre (Cu): Los ovinos son muy sensibles al exceso de cobre en la dieta. El cobre destruye los glóbulos rojos y la orina de los animales se observa de color café muy oscuro y espumosa (Tórtora, 2017).

Toxemia de la preñez: Es una enfermedad que se presenta en las últimas cuatro semanas de la gestación; ocurre principalmente en ovejas con baja condición corporal $(<2.5)$ que gestan dos o más crías, así como también, en ovejas muy gordas, en las cuales el apetito está disminuido. La enfermedad es consecuencia del déficit energético, producto del desbalance entre el aporte de los alimentos y el gasto del animal (Tórtora, 2017).

Hipocalcemia: El término hipocalcemia significa que el nivel de calcio en la sangre está disminuido; se presenta en el último mes de gestación o en las primeras semanas post parto (González y Tapia, 2017).

Hipomagnesemia: Es la deficiencia de magnesio en la sangre; su ocurrencia está relacionada con bajos niveles de magnesio cuando el pasto tiene rápido crecimiento (inicio de lluvias), así como también, por alto contenido de potasio y nitrógeno o bajo contenido de calcio en la dieta. Se presenta generalmente entre una y cuatro semanas después del parto. Las ovejas por lo general, presentan también bajo contenido de calcio en sangre, por lo que se aconseja tratar siempre la hipomagnesemia con calcio y magnesio (González y Tapia, 2017).

Acidosis ruminal: En contraparte a la condición de cetosis, la acidosis ruminal es consecuencia de una dieta energética, con azúcares de fácil digestión, almidón (granos, concentrados, harinas, papas) o azúcares más simples (disacáridos), cuando se utiliza melaza o bagazos de frutas, como aporte energético o como saborizante. (Tórtora, 2017). 
Timpanismo: Se refiere a la acumulación excesiva de gas libre o en forma de espuma en el rumen y la incapacidad para eliminarlo a través del eructo. Las causas que lo originan son múltiples y de acuerdo a esto se le ha clasificado como timpanismo primario o espumoso y timpanismo secundario o gaseoso (Soberón, 2015).

Urolitiasis: La urolitiasis se origina por el exceso de sales minerales en la dieta, donde los mecanismos de eliminación del animal están saturados. Cuando el contenido de sales minerales de la dieta es excesivo, o está dificultada su eliminación, la cristaluria (cristales en la orina), comienza a aumentar y el animal corre riesgo de sufrir una obstrucción de sus vías urinarias (Gioffredo, 2011).

\section{ANÁLISIS Y DISCUSIÓN}

La alimentación en los sistemas de producción animal es el factor más relevante, porque, gracias a su manejo y estructuración adecuados, el componente genético puede expresar su máximo potencial, mientras que las condiciones sanitarias propias de los animales se mantienen, viéndose reflejadas en unos parámetros zootécnicos sobresalientes y la rentabilidad esperada en la granja ovina; por lo tanto, se debe tener en cuenta las diferentes variables (requerimientos-oferta alimenticia) para cada etapa productiva de los ovinos, debido a las limitantes presentadas en la mayoría de los predios, por desconocimiento o por generalizar la alimentación enfocándose únicamente en cantidad del producto y su apariencia organoléptica, sin diferenciar el ciclo productivo; pasando por alto la composición nutricional de los recursos alimenticios, los requerimientos nutricionales específicos y estrategias de suplementación de acuerdo a la condición individual de las hembras (etapa y tipo de gestación o lactancia). Otro de los elementos relevantes para elaborar el modelo de alimentación para rumiantes, es el costo de las materias primas, puesto que los productores, buscando la disminución de costos se arriesgan usando recursos forrajeros o subproductos de cosecha de baja calidad para hacer "productiva" su empresa (Romero y Bravo, 2012). 
Por las condiciones agroecológicas intertropicales, la alimentación de los ovinos se puede basar exclusivamente en pastos, forrajes, subproductos de cosecha y procesamiento de los mismos (heno-ensilaje), para afrontar la época de sequía (alta demanda-baja oferta) y mantener la productividad dentro de los índices establecidos (Vega, 2017). Donde se cuentan con varias especies vegetales con potencial energético (gramíneas) y proteico (leguminosas, arbustivas y arbóreas), las cuales, con el manejo óptimo (establecimiento, fertilización, aprovechamiento y renovación) para pastoreo, corte y acarreo, ramoneo o su conservación, brindan la suficiencia nutricional para mantenimiento de una granja ovina durante cualquier periodo productivo (Vega, 2017). No obstante, por la baja capacitación, limitación de recursos financieros y baja tecnificación disponible por parte de algunos ovinocultores en determinadas regiones, se realiza un manejo alimenticio inadecuado.

La principal característica por la cual se puede realizar un análisis real de la eficiencia del plan de alimentación de un sistema ovino, es la condición corporal, la cual se debe determinar sobre (palpación de apófisis transversas lumbosacras) el animal únicamente, teniendo valores desde 1 a 5 dependiendo de la etapa fisiológica, para permitir tomar correctivos y hacer los ajustes de acuerdo a las necesidades particulares (Giraudo et al., 2014). La condición corporal para las hembras en el inicio a la época de monta (>3), se permite disminuir (2.5-2.7) por el desgaste energético del ciclo estral y evitar el engrasamiento del tracto reproductivo; para la llegada a la gestación tardía y el parto, la oveja debe haber recuperado la puntuación del inicio del periodo reproductivo $(>3)$, logrando afrontar una lactancia con 2 o más corderos, haciendo énfasis en una suplementación especial por la capacidad de ingesta reducida (aumento del tamaño uterino y disminución del rumen), la alta calidad nutricional de la dieta y palatabilidad.

La ganadería ovina en Colombia se distribuye de acuerdo a la disponibilidad de recursos en la zona y cercanía a ciudades capitales, donde predomina el tipo de manejo mixto (bovinos-ovinos) en sistema extensivo, con estructura de economía campesina para autoconsumo y venta en mercados locales (Vivas, 2013). En zonas 
tropicales bajas, se cuenta con recursos genéticos diversos, correspondientes a cruces y mestizajes entre razas pelibuey, ovino de pelo colombiano (OPC) y recientemente la introducción de katahdin, en zonas agroecológicas de baja o nula aptitud agrícola y alta incidencia de predadores para la especie, nivel tecnológico bajo, con un número no mayor a 50 animales, para producción únicamente de carne (Martínez et al., 2009). Establecidos en áreas no mayores a 2 hectáreas, con el interés de la introducción de nuevos recursos genéticos a fin de complementar los existentes, mejorando principalmente la prolificidad, habilidad materna (Black Belly y Santa Inés) y capacidad cárnica (Dorper y Charollais).

Los sistemas de alimentación en el trópico bajo, se pueden establecer con arreglos pastoriles y áreas para cosecha de forrajes, en los diferentes tipos de manejo como lo son pastoreo racional Voisin (PRV), con sus cuatro principios fundamentales que son: 1) Tiempo de recuperación óptimo de la planta, 2) Tiempo adecuado de ocupación ( $<3$ días), 3) Capacidad de carga de acuerdo a la productividad de la pradera (animales/hectárea) y 4) Rendimiento máximo del forraje; sistema silvopastoril (SSP), asociando el estrato bajo (pradera), estrato medio (arbustivo) y alto (arbóreo), estos últimos dentro de la pradera para brindar sombra, follaje proteico, fijación de nitrógeno atmosférico o cercas vivas; bancos energéticos o de proteína, los cuales son áreas de cultivo para corte y acarreo de forraje para suministro en fresco o para su procesamiento y conservación como heno o ensilaje, (Vega 2017).

En los planes de alimentación (granjas convencionales) por grupo etario o etapa fisiológica casi nunca se consideran las diferencias o se tiene en cuenta la suplementación adecuada, generando desbalances nutricionales en corderos y ovejas, restringiendo el crecimiento de los animales jóvenes, la posibilidad de gestaciones múltiples y lactancias apropiadas, debido al elevado requerimiento proteico (120-180 g/día) en animales menores de 6 meses y gestación tardía (116 g/día), necesidades energéticas en lactancia (3.85 Mcal/día) como niveles de calcio (6.7 g/día) y fósforo (5.7 g/día) (Castellaro et al., 2015). 
Por el uso tradicional de suplementos minerales para bovinos en granjas ovinas, comúnmente existen insuficiencias de micro minerales, como el zinc (Zn, $20 \mathrm{mg} / \mathrm{kg})$, selenio (Se, $0.1 \mathrm{mg} / \mathrm{kg}$ ) y cobre ( $\mathrm{Cu}, 5 \mathrm{mg} / \mathrm{kg}$ ), generando bajos índices reproductivos (tasa de concepción, porcentaje de supervivencia y días abiertos) y productivos (ganancia de peso y producción lechera), los cuales se pueden suplir con el manejo de una sal específica para ovinos o soluciones parenterales de manera periódica.

Las condiciones sanitarias del ganado ovino, dependen directamente de la calidad de la alimentación, pues la condición corporal, los niveles de glucosa en sangre y proteínas plasmáticas (albumina y globulinas), varían acorde a la concentración y metabolización de los nutrientes de la ración, correlacionados con la carga parasitaria en el individuo, porque estos afectan inversamente la absorción y disponibilidad de las moléculas activas.

La mayoría $(70 \%)$ de los puntos críticos en la producción ovina tropical, se encuentran el relacionados con en el manejo de la alimentación, en actividades como el balanceo de dieta (requerimientos), palatabilidad de la ración (consumo), digestibilidad de las materias primas (aprovechamiento), almacenamiento (inocuidad) y rentabilidad (costos y productividad); el 15\% está relacionado con en el manejo administrativo, y a su vez con la calidad del recurso humano, el análisis de la información (registros), la evaluación de datos y variables (observaciones detalladas), la identificación de debilidades y el fortalecimiento empresarial (mercadeo y comercialización); el $10 \%$ en la genética, con los parámetros zootécnicos (objetivos productivos y bondades de la raza o cruce) y la heredabilidad (parámetros a mejorar y razas adecuadas); y en el restante $5 \%$ se incluyen la medicina preventiva, bioseguridad y tecnificación. La función principal del manejo es la implementación de un sistema, aprovechando al máximo todos los recursos de una propiedad agropecuaria para lograr ciertos objetivos económicos, teniendo en cuenta los factores principales que determinan el sistema óptimo según las condiciones). Los tipos de razas y esquemas de mejoramiento o selección genética hay que evaluarlos con un profesional especializado en el área, al igual el balanceo 
de la dieta y los demás ítems para garantizar rentabilidad constante en la granja, (Flórez et al., 2018).

\section{CONCLUSIONES}

En la producción ovina, la condición corporal es el parámetro más importante para evaluar la eficiencia de la alimentación, porque está relacionada directamente con la calidad y composición de la dieta; esta práctica se debe realizar periódicamente (una vez/semana), con el fin de permitir al productor conocer las variables nutricionales establecidas para cada etapa para efectuar los ajustes requeridos, teniendo en cuenta los requerimientos, el análisis bromatológico de las materias primas y su digestibilidad. No obstante, el estado sanitario puede influir en su productividad, siendo indispensable manejar una medicina preventiva poblacional, haciendo énfasis en las etapas de mayor predisposición a estrés (parto, destete, transporte, periodos prolongados de manipulación o ayuno).

Los ovinos con fines para producción cárnica, presentan mayor eficiencia alimenticia respecto a los doble propósito (carne-lana) o los de producción lechera, debido a la capacidad de convertir mejor en músculo, es decir, más rápido y con menos gasto energético, debido a las características de heredabilidad que estas razas presentan en cantidad de alimento ingerido, conversión alimenticia y necesidades energéticas para mantenimiento.

La importancia de contar con un recurso genético adaptable a las condiciones agroecológicas, además conocer situación sanitaria el comportamiento agronómico y calidad nutricional de las especies forrajeras de la región, va a facilitar la implementación de un sistema de producción ovina de carne, donde las variables más importantes en la alimentación son la palatabilidad de la dieta, cantidad de raciones, balance de minerales (macro-microminerales), conversión y finalmente el costo de la misma.

El conocimiento detallado del sistema ovino con fines cárnicos, permite interpretar los principales factores críticos para lograr resultados óptimos en el manejo y engorde de los corderos; es necesario tener en cuenta los porcentajes de fertilidad, 
preñez, natalidad, corderos nacidos vivos y número de corderos lactantes por oveja), todo establecido en protocolos de manejo y flujogramas de procesos, atribuirán una productividad considerable, aún en época de escases forrajera.

La alimentación de los ovinos en la región intertropical está determinada por la eficiencia en el uso de los pastos y forrajes, por las bondades presentadas en periodos de alta pluviosidad con respecto a la biomasa, puesto que los excesos de material vegetal se conservan a manera de heno o ensilaje para ser utilizados en los periodos de época seca. En la gestación avanzada es importante utilizar forrajes con alta degradabilidad y fibra detergente neutro baja (menor del 60\%), por su la alta demanda energético-proteica, donde en ciertos casos por la baja calidad del material vegetal se requiere el asocio en con gramíneas y leguminosas, sea en SSP en pastoreo o bancos forrajeros para corte y acarreo, garantizando así una alimentación netamente forrajera con uso de alimentos concentrados en etapas críticas, ofreciendo la ración en horas de la mañana y en horas de la tarde, permitiendo un pastoreo racional y eficiente.

\section{RECOMENDACIONES}

Se debe hacer el mejoramiento genético y la selección adecuada para llegar a tener una producción ovina competitiva, como lo exige el mercado, pero logrando mantener los recursos genéticos locales por la rusticidad adquirida y la adaptación a determinadas condiciones.

Lograr balancear una ración con las materias primas presentes en la zona para cada etapa productiva o para el crecimiento de corderos y gestación tardía (>100 días); con materiales como yuca, tamo de arroz y subproductos del procesamiento de frutales.

Establecer los modelos de pastoreo en sistema silvopastoril, asesorados por los técnicos especializados, procurando hacer el asocio de gramíneas y leguminosas por tiempo de descanso similar, porque los ovinos aprovechan al máximo el forraje ofrecido en estos arreglos nutricionales. 
Evaluar la productividad y eficiencia de cada forraje en varias producciones ovinas, desde su establecimiento hasta su uso en pastoreo o corte y acarreo, para permitir documentar las variables y definir los mejores para unas condiciones agroecológicas específicas.

Las instituciones de educación superior de Colombia, deben servir de soporte técnico-científico para las necesidades de cada uno de los productores, por lo cual hay que brindar alternativas locales para las inquietudes comunes presentadas últimamente, acorde a la dinámica de comercialización y utilidad de la empresa.

\section{REFERENCIAS BIBLIOGRÁFICAS}

1. American Hamshire Shepp Asossiation (AHSA), Hampshire Breed Standards. 2018. Disponible En: http://www.hampshires.org/about.html

2. Alfonso, J. Comportamiento productivo de ovejas cruza de Ramboulliet (3/4) x East Friesian (1/4) en sistema estabulado, Soledad de Graciano Sánchez, S.L.P., México: Universidad Autónoma San Luis de Potosí. 2013.

3. Allen, V. Creep Grazing: como hacer de la cría vacuna un negocio, Blacksburg, Virginia, USA: Virginia Polytechnic Institute and State University Blacksburg. 1993.

4. American Romney Breeders Association (ARBA). Romney Breed Standard. 2018. Disponible En: http://americanromney.org/about-romneys/breed-standard/

5. Asociación Argentina de Criadores Corriedale, (AACC). Generalidades de la raza Corriedale, Buenos Aires: AACC. 2007.

6. Australian Corriedale Association, (ACA). Guide to Judging and Selection of Corriedale Sheep. 2018. Disponible En: http://www.corriedale.org.au/page.asp? =How\%20to\%20judge\%20a\%20Corriedale

7. Australian Dorper \& White Dorper (AD\&WD). Development of Dorper, Goodwood, South Australia: AD\&WD. 2016.

8. Banchero, G., Montossi, F., Ganzábal, A., Alimentación estratégica de corderos: La experiencia del INIA en la aplicación de las técnicas de alimentación preferencial de corderos en el Uruguay, Montevideo, Uruguay: Instituto Nacional de Investigación Agropecuaria - INIA. 2006.

9. Barrios, C. Elección de la raza en la granja ovina, Bogotá D.C.: ASOOVINOS - CAOC. 2018.

10. Bécquer, U. Heredabilidad y correlaciones genéticas y fenotípicas para caracteres de crecimiento en el camaron blanco Litopenaeus schmitti (Burkenroad, 1936) (Decapoda, Dendrobranchiata), La Habana, Cuba: Universidad de la Habana. 2005.

11. Bianchi, G., Garibotto, G., Betancur, O. Efecto de la raza paterna (Corriedale, Texel, ĺle de France y Milchschaf) y del sexo sobre la producción de carne en la progenie de ovejas Corriedale en Uruguay. Información Técnica Económica Agraria - ITEA, 98A (1): 59-73. 2002.

12. Bueno, M., Da Cunha, E., Dos Santos, L., Veríssimo, C. Santa Inês: Uma Boa Alternativa para a produção intensiva de carne de cordeiros na Região Sudeste, Sao Paulo, Brasil: Secretaria de Agricultura e Abastecimiento do Estado de Sao Paulo. 2017.

13. Camargo, A., Contexto y producción ovina y caprina en Colombia, Bogotá D.C.: Cadena Ovino Caprina - MADR. 2016.

14. Cansino, G., Herrera, J., Aké, J. Tasas de concepción, fertilidad y prolificidad en ovejas de pelo alimentadas con dietas enriquecidas con ácidos grasos polinsaturados. Universidad y Ciencia, 2: 181-185. 2009.

15. Castellanos, J., Rodríguez, J., Toro, W., Luengas, C. Agenda prospectiva de investigación y desarrollo tecnológico para la cadena productiva cárnica ovino - Caprina en Colombia, Bogotá D.C.: Ministerio de Agricultura y Desarrollo Rural. 2010.

16. Castellaro, G. Principios de la genética animal aplicados al mejoramiento de la producción de carne ovina. Santiago de Chile: Universidad de Chile, Facultad de Ciencias Agronómicas. 2016. 
17. Castellaro, G., Orellana, C., Escanilla, J. Manual básico de nutrición y alimentación de ganado ovino. Santiago de Chile: Universidad de Chile: Facultad de Ciencias Agronómicas. 2015.

18. Cordero, R., Monge, F., Villalobos, V. Especies menores: Ovejas, San José de Costa Rica: Universidad Estatal a Distancia de Costa Rica. 2016.

19. Cordova, A., Costa, R., Araújo, J., Alves, N. Desempeño de ovinos de la raza Santa Inês alimentados con nopal y restricción de agua. Actas Iberoamericanas de Conservación Animal, p 267-269. 2014.

20. Creangâ, S., Maciuc, V., Coman, M. Estimates of heritability coeficients in some sheep populations from the sheep breeding research station of Palas-Constanta, lasi, Rumania: University of Agricultural Sciences and Veterinary Medicine of lasi. 2007.

21. Cruz, F., Rodríguez, D., Benavides, A., Clavijo, J. Caracterización de parámetros productivos y reproductivos de ganado normando en Colombia. Archivos de Zootecnia, 62 (239): 345-356. 2013.

22. Departamento Administrativo Nacional de Estadística (DANE). Encuesta de Sacrificio de Ganado ESAG: IV Trimestre de 2018, Bogotá D.C.: DANE. 2018.

23. Espinal, C., Martínez, H., Amézquita, J. La cadena de ovinos y caprinos en Colombia: Documento de trabajo N. 125, Bogotá D.C.: MADR - AGROCADENAS. 2006.

24. Esqueda, M., Gutierrez, E. Producción de ovinos de pelo bajo condiciones de pastoreo extensivo en el Norte de México. Chihuahua, México: INIFAP - SAGARPA. 2009.

25. Ferrer, A. I Curso de actualización en selección y juzgamiento de razas criollas de pelo. Montería, Córdoba, ASOVICOR, p 77. 2017.

26. Flórez, J., Hernández, M., Bustamante, M., Vergara, O. Caracterización morfoestructural de tres poblaciones de ovino de pelo criollo colombiano "OPC". Archivos de Zootecnia, 67 (259): 340-348. 2018.

27. Fogarty, N. Utilization of breed resources for sheep production, Belo Horizonte, MG, Brazil: $8^{\text {th }}$ World congress on genetics applied to livestock production. 2006.

28. Franco, L., Calero, D., Durán, C. Manual de establecimiento de pasturas, Palmira, Valle del Cauca: CIAT. 2007.

29. Galaviz, J., Zaragoza, J., Corona, V. Alimentación para Ovinos de la Región Nor - poniente de Tlaxcala, Tlaxcala, México: INIFAP - SAGARPA. 2011.

30. Ganzábal, A, Lira R, Urgate E, Franco B, Bermudez J, Bidot A (Ed). Guía práctica de producción ovina en pequeña escala en Iberoamérica. Montevideo, Uruguay: Ciencia y Tecnología para el Desarrollo - CYTED. 2016.

31. García, G., Pérez, G. Uso y manejo de pastizales en la cría intensiva de ovinos y caprinos, Caracas, Venezuela: Complejo Editorial Alfredo Maneiro - CEAM. 2017.

32. Gioffredo, J. J. Sanidad en ovinos y caprinos: Enfermedades metabólicas, Río Cuarto, Córdoba, Argentina: Universidad Nacional de Río Cuarto. 2011.

33. Giraudo, C., Villar, M., Villagra, E. Engorde de ovinos y caprinos a corral, San Carlos de Bariloche, Argentina: INTA. 2014.

34. Godfrey, S., Boyce, M., Rowe, J., Speijers, E. Changes within the digestive tract of sheep following engorgement with barley. Australian Journal of Agricultural Research, 44 (5): 1093-1101. 1993.

35. González, V., Tapia, M. Manual de manejo ovino. Santiago de Chile: Instituto de Desarrollo Agropecuario - Instituto de Investigaciones Agropecuarias. 2017.

36. Huerta, M. Alimentación de Ovinos con Dietas Basadas en Forrajes de Corte, Chapingo, México: COLPOS - UACh. 2016.

37. Instituto Colombiano Agropecuario, (ICA). Censo población de ovinos, Bogotá D.C. 2018.

38. IFSBSSA. Administrative Guide: Breeding, Bloemfontein, South Africa: lle de France Sheep Breeders' Society of South Africa. 2017.

39. Joy, M. et al., Opciones para la producción de Corderos Ligeros. En: Guía práctica de producción ovina en pequeña escala en Iberoamérica. Montevideo, Uruguay: Ciencia y Tecnología para el Desarrollo - CYTED, p 21-26. 2016.

40. Leymaster, K. Fundamental aspects of crossbreeding of sheep: Use of breed diversity to improve efficiency of meat production. Sheep and Goat Research Journal, 17 (3): 50-59. 2002.

41. Lôbo A, Lôbo R, Paiva S, Pinheiro S, Facó O. Genetic parameters for growth, reproductive and maternal traits in a multibreed meat sheep population. Genetics and Molecular Biology, 32 (4): 761770. 2009.

42. Martínez, M. La técnica del flushing en la alimentación de ovejas, Osorno, Chile: INIA - Remehue. 2012.

43. Martínez, R., Vásquez, R., Ballesteros, H. El ovino criollo en colombia, conservación, caracterización y evaluación de la variabilidad genética. en: biodiversidad ovina iberoamericana: caracterización y uso sustentable. Punta del Este, Uruguay: Universidad de Córdoba, p 235-261. 2009. 
44. Mathis, C., Ross, T. Sheep production and management. cooperative extension service, p 1-44. 2005.

45. Montes, D., Perez, A., De la Ossa, J. Importancia de los ovinos en los sistemas de producción pecuario: Perspectiva. Revista Colombiana de Ciencia Animal, VIII (1): 5-6. 2016.

46. Morand-Fehr, P., Boyazoglu, J. Present state and future outlook of the small ruminant sector. Small Ruminant Research, 34 (3): 175-188. 1999.

47. Mujica, E. Boletín INIA № 127: Razas ovinas y caprinas en el Instituto de Investigaciones Agropecuarias, Osorno, Chile: Ministerio de Agricultura: INIA. 2005.

48. Ochoa, P. Mejoramiento genético del ganado bovino productor de leche. Ciencia Veterinaria, p 6885. 1991.

49. Organización de las Naciones Unidas (FAO). Organización de las Naciones Unidas para la Alimentación y la Agricultura. 2018. Disponible En: http://www.fao.org/dairy-productionproducts/production/productiondairy-animals/productiondairy-animalssmall-ruminants/es/

50. Otte, M., Chilonda, P. Cattle and small ruminant production systems in Sub-Saharan Africa: A Systematic Review. Roma, Italia: FAO. 2002.

51. Parish, J., Rivera, J., Boland, H. Understanding the ruminant animal digestive system, city of Jackson, Mississippi, USA: Mississippi State University. 2017.

52. Partida, J, Rios F; de la Cruz I, Dominguez I, Buendía. Caracterización de las canales ovinas producidas en México. Rev Mex Cienc Pecu., 8 (3): 269-277. 2017.

53. Pezzanite, L., Neary, M., Hutchens, T., Scharko, P. Common diseases and health problems in sheep and goats, West Lafayette, Indiana, USA: University of Purdue. 2010.

54. Redondo, P. Área de zootecnia y producción animal: Anatomía del aparato digestivo de un rumiante, Valladolid, España: Escuela Universitaria de Ingeniería Técnica Agrícola - INEA. 2003.

55. Relling, A., Matiolli, G. Fisiología digestiva y metabólica de los rumiantes. La Plata, Bs As, Argentina: Universidad de La Plata: Facultad de Ciencias Veterinarias. 2003.

56. Romero, J. Zootecnia de Ovinos: Importancia de los productos y derivados de los ovinos, México D.F.: FMVZ - UNAM. 2010.

57. Romero, O., Bravo, S. Fundamentos de la producción ovina en la región de La Araucanía, Temuco, Chile: Instituto de Investigaciones Agropecuarias - INIA. 2012.

58. Rúa, C., Pabón, F. Manual técnico para la producción de carne ovina utilizando Buenas Prácticas Ganaderas. Medellín, Colombia: Gubernation de Antioquia. 2015.

59. Saskatchewan Sheep Development Board (SSDB). Sheep Nutrition Fact Sheet, Saskatoon: Agriculture and Agri-Food Canada. 2017.

60. Soberón, A. Timpanismo Ruminal en Caprinos, México D.F.: FMVZ - UNAM. 2015.

61. Tórtora, J. Tecnología para Ovinocultores: Enfermedades metabólico - nutricionales, México D.F.: Unión Nacional de Ovinocultores - UNO. 2017.

62. Vásquez, E., Partida, J., Rubio, M., Méndez, D. Comportamiento productivo y características de la canal en corderos provenientes de la cruza de ovejas Katahdin con machos de cuatro razas cárnicas especializadas. Revista Mexicana de Ciencias Pecuarias, p 247-258. 2011.

63. Vega, C. Prácticas ganaderas en sistemas de producción de ovinos: Desafíos para el mejoramiento de la competitividad del sector en Colombia. Bogotá D.C.: Universidad Nacional de Colombia - UN. 2017.

64. Vega, C., García, D. Guía práctica para pequeños productores ovinos: Fundación Holcin de Colombia, Tunja, Boyacá, Colombia: Jotamar Ltda. 2011.

65. Velázquez, B. et al., Ciencias biológicas y de la salud: Nutrición Ovina. Pachuca, México: Universidad Politécnica de Pachuca - ECORFAN. 2017.

66. Vivas, N. Diversidad genética de ovinos criollos Colombianos, Palmira, Valle del Cauca, Colombia: Universidad Nacional de Colombia. 2013. 